\title{
Reply to Biodiversity data are out of local taxonomists' reach
}

In complement to what was mentioned by Donat Agosti, from the American Museum of Natural History, wrote in his letter published by Nature 439,392 -26 January 2006 some developing countries are doing a tremendous effort to help solving the taxonomic problems related to biodiversity conservation and sustainable use.

In Brazil, for instance, The State of São Paulo Research Foundation/FAPESP started the BIOTA/FAPESP Program, a research program on characterization, conservation and sustainable use of the biodiversity of the State. With an annual budget of approximately US\$2.500.000,00 (15 million dollars in six years) the BIOTA/FAPESP tackled the taxonomic problems by: a) recovering the status of Taxonomy as a major science area, recognizing the importance of training new taxonomist (supported by MSc or PhD scholarships) and to support research projects on inventories and taxonomic revisions; b) establishing a standard protocol for recording biological information generated by inventories, and developing the tools to integrate biological data (http://sinbiota.cria.org.br/) with a sophisticated GIS (http://sinbiota.cria.org.br/atlas/); c) developing a Distributed Information System that integrates primary data from scientific biological collections (http://splink.cria.org.br/) to recover and make freely available all information deposited in biological collections.

In six years the BIOTA/FAPESP produced a detailed 1:50.000 Atlas of the remnants of native vegetation (mainly Mata Atlântica - Atlantic Rain Forest and Cerrado - savannah, both considered as biodiversity hotspots by Myers et al (Nature 403, 853-858 - 24 February 2000 ), supported 75 major research projects - which trained successfully $150 \mathrm{MSc}$ and $90 \mathrm{PhD}$ students, produced and stored information about approximately 10.000 species and managed to link and make available data from 35 major biological collections.

Furthermore, to tackled the question of publication the BIOTA/FAPESP Program launched, in 2001, the electronic peer reviewed journal BIOTA NEOTROPICA, that publishes the results of original research (associated or not with the BIOTA/FAPESP Pragram) on biodiversity characterization, conservation and sustainable use within the Neotropical region. In five years the journal is becoming an international reference for in its area and it's already indexed by QUALI/CAPES, Zoological Record, CAB International and Directory of Open Access Journals. This year it will be evaluated by Thomson Scientific to be indexed by ISI Web of Knowledge, the Web of Science and Current Contents.

Last, but not least, considering the high quality of the biological information produced by the BIOTA/FAPESP Program we decided to organize a network of researchers and laboratories with the objective of establishing the basis for the sustainable use of our biodiversity. As a result now we have the BIOprospecTA - São Paulo State Bioprospecting Network as a subprogram of the BIOTA/FAPESP program.

In an effort to reach the non academic public and increase society's awareness on the crucial importance of biodiversity conservation and sustainable use the BIOTA/FAPESP has also produced videos, presented in open TV programs, expositions, folders, field guides and books.

As said by the international Scientific Advisory Board that evaluates the BIOTA/FAPESP Program "science in most BIOTA projects is of high quality equivalent or exceeding to that in other countries and in several projects it is of outstanding quality at the cutting edge of international efforts. In many respects the BIOTA program provides an example and sets standards that many countries would be happy to follow".

The BIOTA/FAPESP Program is the result of the articulation of the scientific community of the State of São Paulo, with the backing of the Scientific Directory of FAPESP, to take concrete actions for the implementation of the Convention on Biological Diversity, signed in 1992 during UN's Earth Summit in Rio de Janeiro.

Similar initiatives are under way at the Federal level in Brazil with the PPBio/MCT an in other megadiverse countries like Mexico with CONABIO, Costa Rica with INBIO and Africa with the BIOTA Africa. So, developing countries are fully aware of their responsibilities regarding the Convention on Biological Diversity and are looking for partners to share the costs of the outrageous task we have, regarding characterization, conservation and sustainable use of our greatest asset: biodiversity. 